ECCOMAS

Proceedia
COMPDYN 2021

$8^{\text {th }}$ ECCOMAS Thematic Conference on Computational Methods in Structural Dynamics and Earthquake Engineering

M. Papadrakakis, M. Fragiadakis (eds.)

\title{
NUMERICAL ANALYSIS ON SHALLOW FOUNDATIONS LATERAL DISCONNECTION
}

\author{
Fausto Somma $^{1}$, Alessandro Flora ${ }^{1}$, Emilio Bilotta $^{1}$ and Giulia Viggiani $^{2}$ \\ ${ }^{1}$ University of Naples Federico II \\ Via Claudio 26, NA \\ fausto.somma@unina.it,flora@unina.it,bilotta@unina.it \\ ${ }^{2}$ University of Cambridge \\ Trumpington Street, Cambridge CB2 1PZ, UK \\ gv278@cam.ac.uk
}

\begin{abstract}
The paper presents a numerical study aiming at establish the effects of removing the lateral ground connection between embedded shallow foundations and surrounding soil on dynamic soil-structure interaction. Series of two-dimensional finite element models were developed comparing the behaviour of two identical structures with just one difference: the embedment of their own foundations. In order to find the parameters that most influenced the effect of the lateral disconnection technique, the properties of the two structures (predominant period, aspect ratio, loading bearing, foundation embedment) as well as the ones of the soil were parametrically varied. From the results gathered in here, it was established the effectiveness of the proposed system to reduce the inter-story drifts demand on the structures and increase their predominant periods specially in case of high value of foundation embedment in a medium dense soil.
\end{abstract}

Keywords: Soil-structure interaction, Seismic actions mitigation, Period Elongation, Geotechnical Seismic Isolation. 


\section{INTRODUCTION}

The geotechnical seismic isolation techniques transpose the effects of traditional isolation techniques, such as rubber or sliding bearing isolator, into the ground[1]. Several geotechnical seismic isolation strategies have been outlined over time. It has been shown experimentally and numerically that the creation of a surface with a low friction angle, immediately below the foundations, is able to dissipate the energy of earthquakes [2]. Similarly, the creation of an isolated volume of soil, through the use of vertical and horizontal soft barriers, is able to significantly reduce the accelerations in the volume itself [3]. Furthermore, the effectiveness of sandrubber mixtures, in mitigating seismic accelerations, was demonstrated through numerical models and fields test [4]. All the procedures outlined have, as a common strategy, to increase the natural period or damping of the soil-structure system. An inexpensive and intuitive way to achieve this is to laterally disconnect the shallow foundations of a structure from the adjacent lateral soil as both the rotational and translational stiffness of soil-structure foundation decrease and, consequently, the equivalent natural period, computing the soil structure interaction, will increase [5]. The elongation of the natural period has as a direct consequence a different demand in terms of accelerations and displacement on the structure.

This article refers on a parametric analysis where the period elongation of the structure with the lateral disconnection is compared with the same structure laying on fully embedded foundation in the ground. Different parameters in the structure, such as the aspect ratio, the fixed base period, the embedded of the foundation, have been changed as well as the stiffness properties of the soil. Finally, a series of multiple real earthquakes have been applied to a single scenario with a specific seismic hazard to numerically highlight the potentiality of such G.S.I technique.

\section{NUMERICAL ANALYSIS}

\subsection{Numerical model}

The numerical analysis were carried out by the use of the software Plaxis $2 \mathrm{D}$. The finite element model is presented in Figure 1.

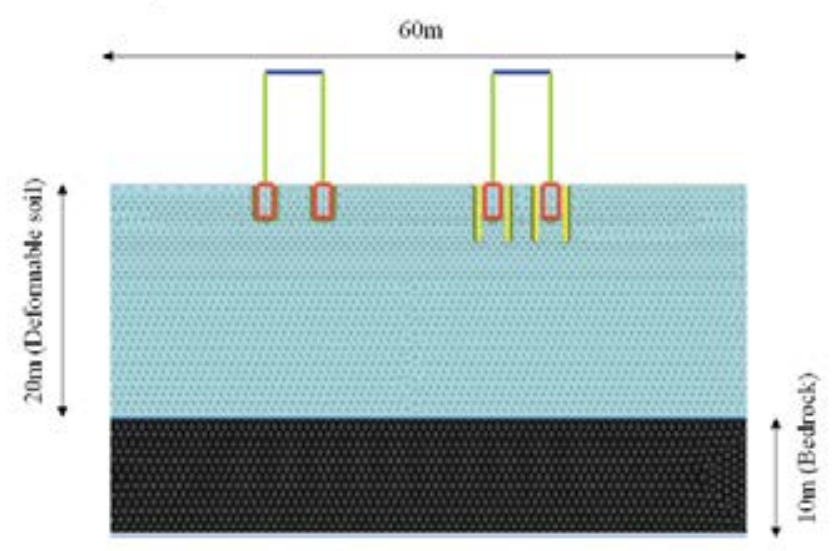

Figure 1. Numerical model with the indication of width and depth of the soil domain and the mesh adopted.

The model has a width dimension of $60 \mathrm{~m}$ and a total depth of 30 meters. The width of the deformable soil is fixed at 20meters while 10 meters of bedrock are included in the model to ensure no significative interference between the bottom base and the soil layer. The ground water is absent. Standard boundary conditions were applied during the initial (static) stage, that 
is zero horizontal displacements along the lateral boundaries and fixed nodes at the base of the grid. During the dynamic analysis, the seismic inputs were applied to the bottom nodes of the mesh. In order to take into account the finite stiffness of the underlying bedrock, and to reproduce the upward propagation of shear waves within a semi-infinite domain, the outcrop input accelerations were halved to compute the corresponding upward-propagating wave motion and applied to the bottom nodes together with adsorbing viscous dashpots. Free-field boundary conditions were applied along the lateral sides of the mesh. The element size of the soil has been taken always smaller than one-tenth of the wavelength associated with the highest frequency component of the input wave containing appreciable energy [6]. For this reason, the discretization was carried out using 7872 tetrahedral elements with 15 nodes each. Both the structures, with and without the lateral disconnection, have been studied in the same numerical model. The relative distance between the two structures (13meter) and between the structures and lateral boundaries of the models (16meters) ensures no significant interaction [7].

\subsection{Static Force and Input Motion Applied}

In order to evaluate the elongation of the natural period generated by the lateral disconnection, the Fourier Trasform of crossbeam free oscillation displacement was calculated for both structures. In particular an horizontal static force is applied on the structure crossbeam to impose an initial condition of motion and then the free oscillation was studied in a dynamic phase deactivating the force itself. The procedure was repeated for all the studied scenario.

Consequently, in order to evaluate the effectiveness of the lateral disconnection in terms of acceleration and Arias intensity reduction, a series of multiple earthquakes were selected and applied at the bedrock. The accelerograms were chosen and scaled by using the software Rexel [8] considering the Elastic Design Spectrum of L'Aquila centre (Italy) with a return period of 475 years, corresponding to the life safety limit states as defined by the Italian Code [9]. Since the earthquakes were selected on soil class A (rock) no deconvolution of the earthquakes is needed. Due to the fact that L'Aquila is one of the most affected Italian cities by the seismic events, the frequency content and intensity of L'Aquila hazard was considered a good reference to highlight the applicability of the proposed technique specially in a contest where the seismic hazard is particularly high. All the informations about the selected earthquakes are reported in Table 1 while Figure 1 shows the spectra compatibility of L'Aquila design spectrum with the selected scaled earthquakes.

\begin{tabular}{|c|c|c|c|c|c|c|c|}
\hline $\begin{array}{l}\text { Record } \\
(-)\end{array}$ & $\begin{array}{l}\text { Location } \\
(-)\end{array}$ & $\begin{array}{c}\text { Year } \\
(-)\end{array}$ & $\begin{array}{l}M \\
(-)\end{array}$ & $\begin{array}{c}\text { NERHP } \\
\text { Site } \\
(-)\end{array}$ & $\begin{array}{c}\text { JB dist } \\
(\mathrm{km})\end{array}$ & $\begin{array}{c}\text { PGA } \\
(\mathrm{g})\end{array}$ & $\begin{array}{l}\text { Arias Intensity } \\
(\mathrm{m} / \mathrm{s})\end{array}$ \\
\hline 1 & Campano Lucano & 1980 & 6.9 & A & 25 & 0.06 & 0.06 \\
\hline 2 & Bingol & 2003 & 6.3 & A & 14 & 0.51 & 1.99 \\
\hline 3 & South Iceland & 2000 & 6.5 & A & 13 & 0.13 & 0.16 \\
\hline 4 & Mt. Vatnafjoll & 1987 & 6.0 & A & 24 & 0.03 & 0.006 \\
\hline 5 & Golbasi & 1986 & 6.0 & A & 29 & 0.03 & 0.01 \\
\hline 6 & Friuli & 1976 & 6.5 & A & 23 & 0.35 & 0.79 \\
\hline 7 & $\begin{array}{l}\text { South Iceland (af- } \\
\text { tershock) }\end{array}$ & 2000 & 6.4 & A & 15 & 0.12 & 0.21 \\
\hline
\end{tabular}


Table 1. Main characteristics of the selected accelerograms, before scaled at the Aquila's PGA, for the earthquake analysis

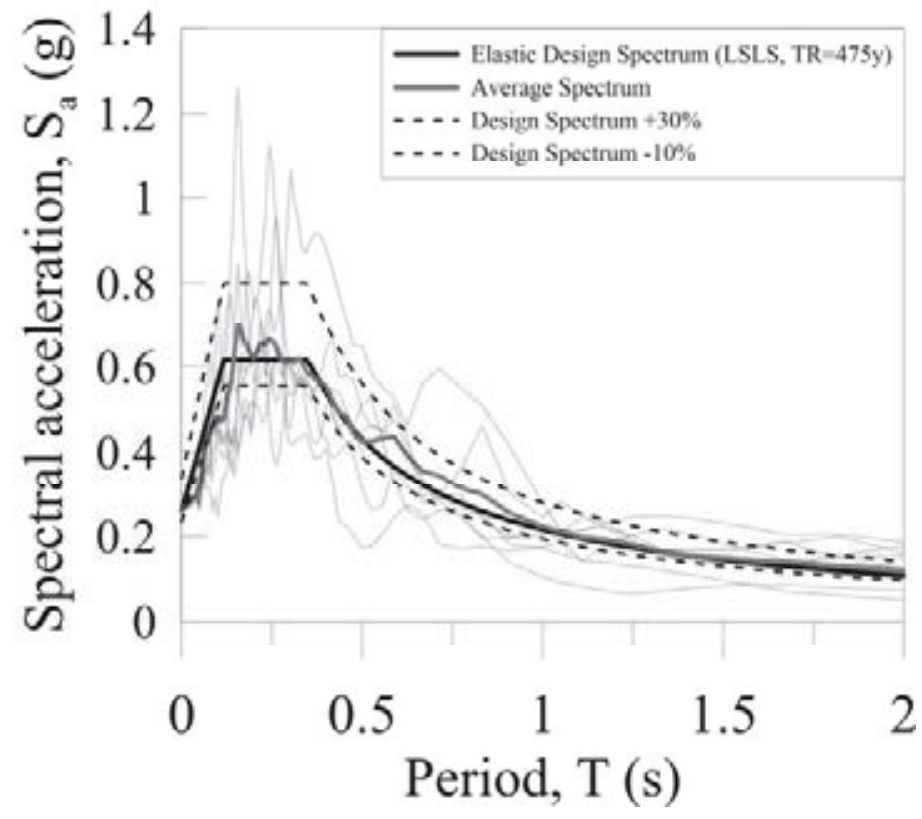

Figure 2. Spectro compatibility of the selected earthquakes with elastic design spectrum of Aquila centre at life safety limit state.

\subsection{Structural models}

The structural model is a linear elastic one bay one frame laying on shallow strip foundations. The foundations of the structures were modelled through the use of a non-porous linear elastic element volume with reinforced concrete properties $\left(E=30000 \mathrm{Mpa}, \mathrm{v}=0.2, \gamma=25 \mathrm{kN} / \mathrm{m}^{3}\right)$ while beam structural element were used to model the columns and crossbeams. The crossbeam length is equal to 5.00 meters while the distance between the strip shallow foundations $(W)$ is equal to 6.36 meters. The SDOF model would represent the main dynamic and static properties of masonry structures. In particular, in order to study the effect of the lateral disconnection on a structure with a different predominant period of vibration, the fixed base period of such structures was set at $0.3,0.5,0.8$ and $1 \mathrm{sec}$, calibrating the stiffness of the columns beam and the mass of the crossbeam. Taking advantage of the Eurocode 8[10] formulation:

$$
T_{\text {fixed_base }}=C_{\mathrm{t}} H^{0.75}
$$

where $T_{\text {fixed_base }}$ is the fundamental period in seconds, $H$ is the height of the building and $C_{\mathrm{t}}=$ 0.05 is a constant depending on the type of earthquake resistant structural system, it is possible to estimate the total height of the prototype structure and, assuming an interfloors height equal to 3 meter, estimate the specific number of floors associated at the fixed base period. Considering an unit load of $10 \mathrm{kPa}$ per floor it is possible to calculate the total mass to assign at the crossbeam and thus the stiffness of the column beam to ensure, respectively, the desired average bearing pressure on the soil and fixed base period. 
In order to study the impact of the aspect ratio on the lateral disconnection technique, three different heights of the structures $(H)$, equal to 4.5, 5.8, 9.8 meters, has been considered. These heights correspond to the structure aspect ratio equal to $0.8-1-1.5$.

The width of the strip footing shallow foundation $(B)$ was fixed at 1.4 meter while the embedment of the foundation $(D)$ was varied from 1.4 to 3.5 meters $(D / B=1-2.5)$.

In order to model correctly the contact between the foundation and the soil, interfaces along the foundation has been used assuming a reduction coefficient of 0.7 for the stiffness and strength properties at the interface. The stability of the small trenches, able to generate the lateral disconnection from the soil, is guaranteed by 4 cantilever walls. The viscous damping ratio of the structure is equal to $5 \%$ and was assigned to the columns beam with the double frequency approach. Table 2 summarize all the structural variable parameters considered to carry out the parametrical analysis and the fixed ones in the earthquake's analysis.

\begin{tabular}{|c|c|c|c|}
\hline Type of analysis & $\begin{array}{l}\text { Fixed Base period } \\
T_{\text {fixed_base }} \\
(\mathrm{s})\end{array}$ & $\begin{array}{c}\text { Aspect Ratio } \\
H / W \\
(-) \\
\end{array}$ & $\begin{array}{c}\text { Foundations Aspect Ra- } \\
\text { tio } \\
D / B \\
(-) \\
\end{array}$ \\
\hline $\begin{array}{l}\text { Parametrical } \\
\text { Analysis }\end{array}$ & $0.3-0.5-0.8-1$ & $0.8-1-1.5$ & $1-1.5-2-2.5$ \\
\hline $\begin{array}{l}\text { Earthquakes } \\
\text { Analysis }\end{array}$ & 0.5 & 1.5 & 1.5 \\
\hline
\end{tabular}

Table 2. Selected variable and fixed parameters for, respectively, the parametrical and earthquake analysis

\subsection{Soil Material models}

In order to evaluate the elongation of the natural period, the deformable soil was modelled as a homogeneous linear visco-elastic layer with different stiffness and damping properties (Table 3). The different stiffnesses of the soil analysed would represent a large spectrum of possible compliant base conditions for the structure. The bedrock has been modelled as visco-elastic half space with a damping ratio of $0.5 \%$.

\begin{tabular}{|c|c|c|c|}
\hline Soil type considered & $\begin{array}{c}\text { Shear modulus } \\
\qquad \begin{array}{c}G \\
\left(\mathrm{MN} / \mathrm{m}^{2}\right)\end{array}\end{array}$ & $\begin{array}{c}\text { Shear waves velocity } \\
V_{S} \\
(\mathrm{~m} / \mathrm{s})\end{array}$ & $\begin{array}{l}\text { Viscous Damping ratio } \\
(\%)\end{array}$ \\
\hline Soil 1 & 200 & 350 & 1.42 \\
\hline Soil 2 & 141 & 300 & 1.60 \\
\hline Soil 3 & 94 & 250 & 2.00 \\
\hline Soil 4 & 58 & 200 & 2.5 \\
\hline
\end{tabular}

Table 3. Different properties of the soil considered to carry out the parametrical analysis.

In order to evaluate the effectiveness of the lateral disconnection in the real earthquake's scenario, an equivalent visco-elastic model was used for the soil. In this case, the properties of Hostun Sand [11], at a relative density of $60 \%$, was used (Table 4). 


\begin{tabular}{|c|c|c|c|}
\hline $\begin{array}{c}\text { Maximum } \\
\text { void ratio } \\
\mathrm{e}_{\max } \\
(-)\end{array}$ & $\begin{array}{c}\text { Minimum void ratio } \\
\mathrm{e}_{\max } \\
(-)\end{array}$ & $\begin{array}{l}\text { Specific gravity } \\
\qquad \mathrm{G}_{\mathrm{s}} \\
(-)\end{array}$ & $\begin{array}{c}\text { Relative Density } \\
\text { RD } \\
(\%)\end{array}$ \\
\hline 1.01 & 0.555 & 2.65 & 60 \\
\hline
\end{tabular}

Table 4. Properties of the Hostun Sand considered in the earthquake analysis.

To evaluate the increase of the shear modulus with depth the equation 1, by Hardin and Drenevich [12], was used with the specific parameter for Hostun Sand found by Hoque and Totquoka [13], (Table 5).

$$
G_{0}=A \cdot f(e) \cdot O C R^{k}\left(\frac{p^{\prime}}{p_{\text {ref }}}\right)^{m}
$$

\begin{tabular}{ccccc}
\hline $\begin{array}{c}\text { Soil } \\
(-)\end{array}$ & $\begin{array}{c}A \\
(-)\end{array}$ & $\begin{array}{c}f(e) \\
(-)\end{array}$ & $\begin{array}{c}k \\
(-)\end{array}$ & $\begin{array}{c}m \\
(-)\end{array}$ \\
\hline $\begin{array}{l}\text { Hostun } \\
\text { Sand }\end{array}$ & 80 & $\frac{(2.17-e)^{2}}{1+e}$ & 0 & 0.47 \\
\hline
\end{tabular}

Table 5. Specific parameters of Hostun Sand find by Hoque and Totquoka.

The different shear stiffness of the soil was assigned in the model considering different horizontal layers. In particular, 8 layers of 1 meter have been used for the first 8 meters while 6 layers of 2 meters have been used for the remaining 12 meters (Figure 3a). The mean curves of Seed and Idriss [14] has been selected to model the shear modulus reduction and the increase of damping with the shear strain (Figure $3 b$ ). 

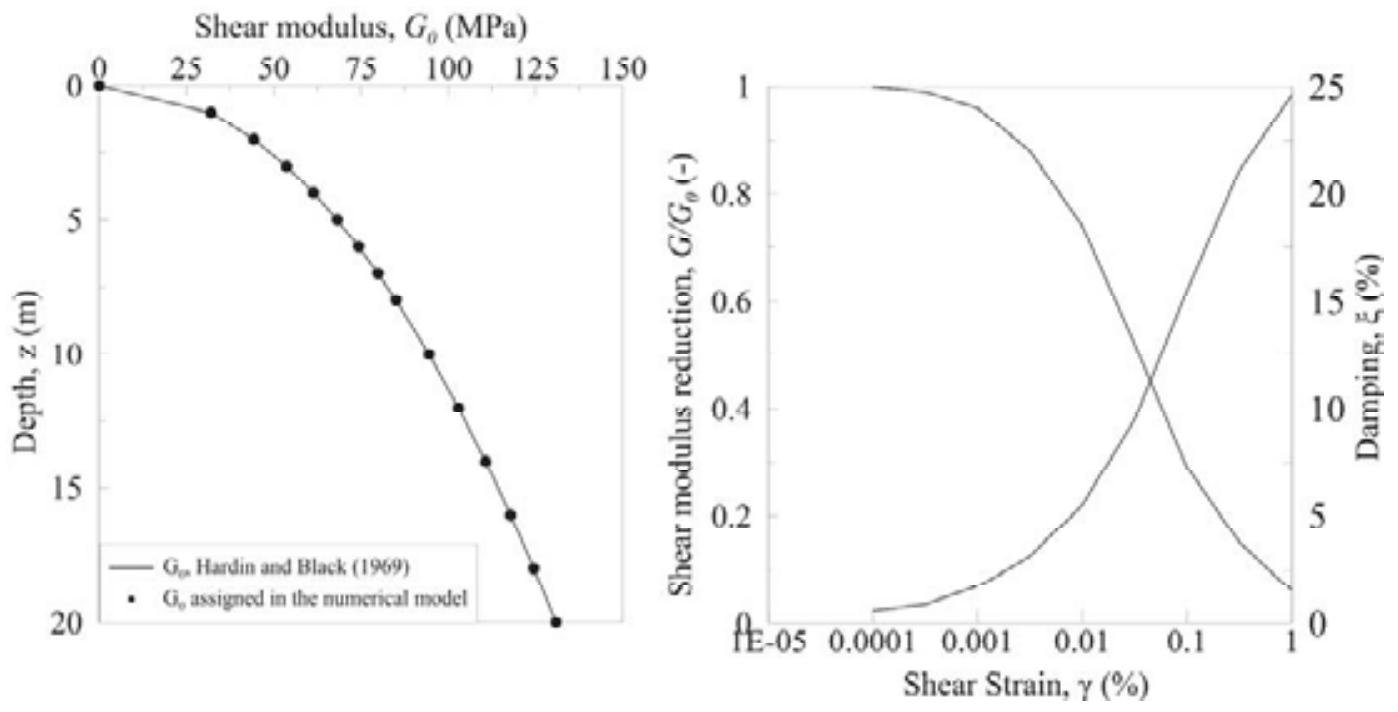

Figure 3. Properties of the sand used for earthquakes analysis: (a) Shear Modulus Profile with depth; (b) Shear modulus reduction and damping increase with shear strain by Seed and Idriss mean curves.

\section{RESULT AND DISCUSSION}

\subsection{Parametrical Analysis}

Figure 4 summarize all the parametrical analysis carried out combining the different variable parameters.

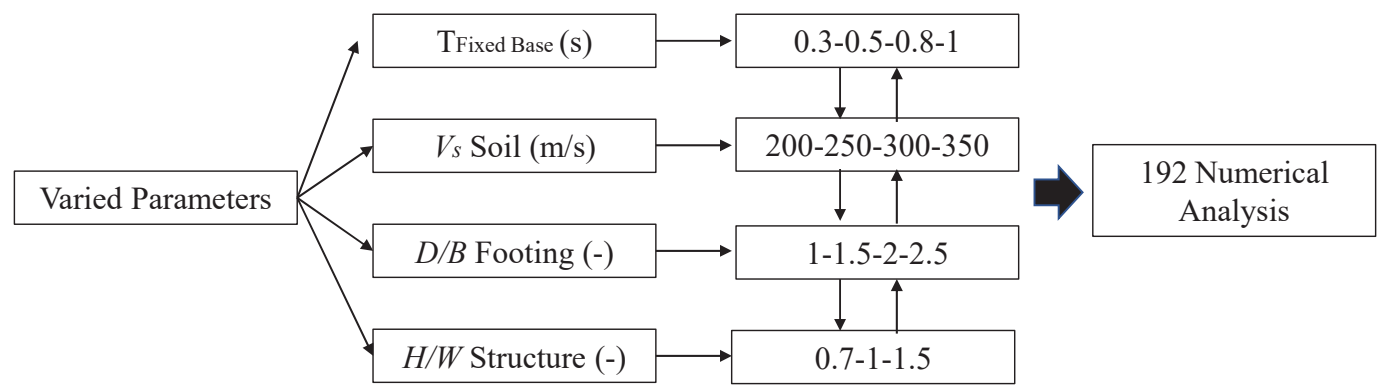

Figure 4. Schematic representation of the parametrical analysis carried out.

From the 192 numerical analysis it was possible to understand the parameters that most influence the period elongation between the two structures. Figure 5 shows the period elongation $\left(T_{\text {Var }}=\left(T_{\text {disc }}-T_{\text {conn }}\right) / T_{\text {conn }}\right)$ as function of the stiffness of the soil for different value of $D / B$ with the aspect ratio $(H / W)$ equal to 0.7 . 

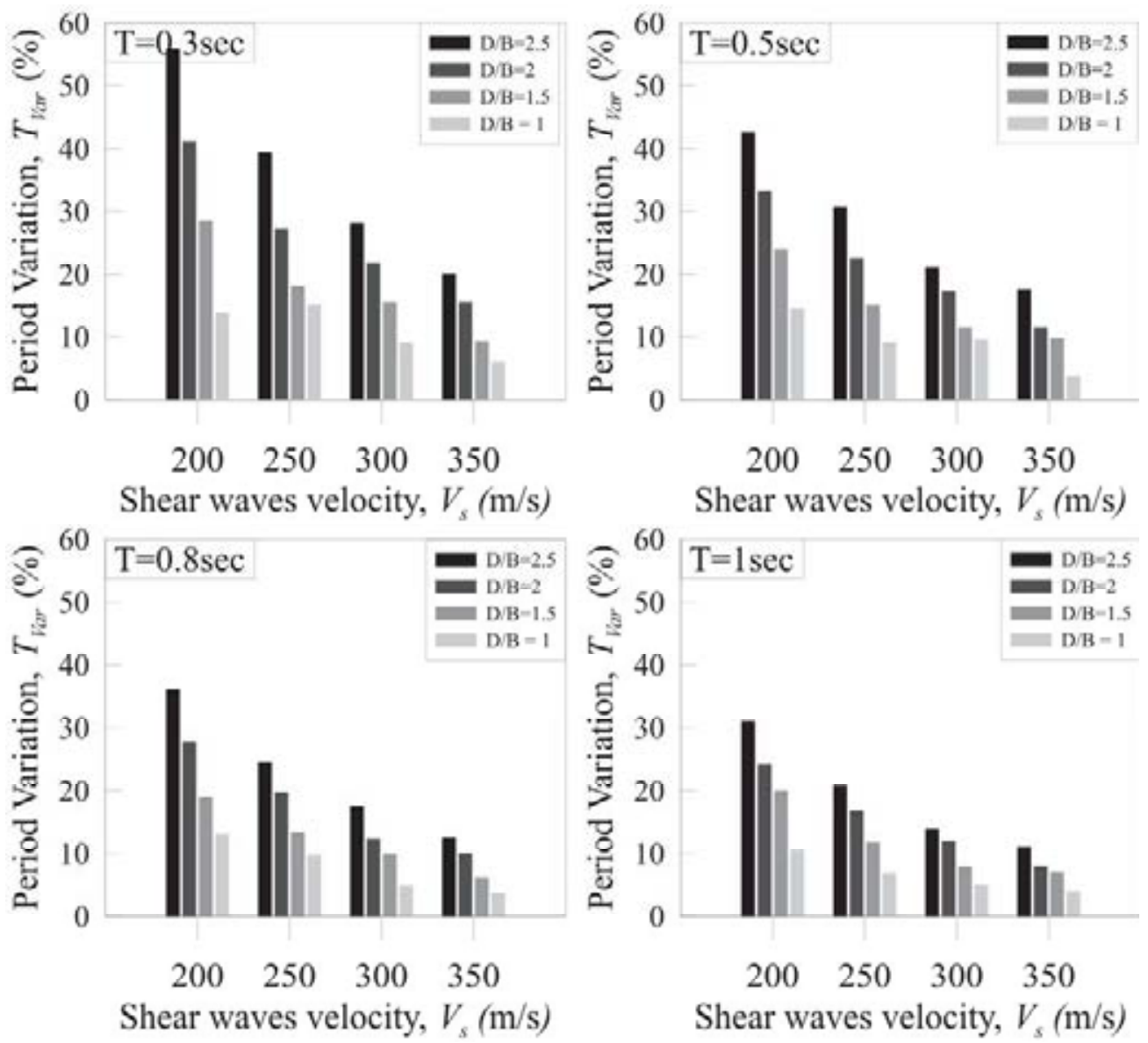

Figure 5. Period variation between the structures with and without lateral disconnection as function of the shear waves velocity and foundation aspect ratio.

It is clear that the period elongation is strictly depended on the value of the ratio $D / B$. In relative terms, scaling from $D / B=1$ to $D / B=2.5$ the period variation increases to $170 \%$ on average all scenarios. However, it is also possible to see, that the period elongation seems to increase as the stiffness of the subsoil decreased. In particular scaling from $V_{S}=350 \mathrm{~m} / \mathrm{s}$ to $V_{S}=200 \mathrm{~m} / \mathrm{s}$ the period elongation is increased by $160 \%$ on average. A possible explanation is that the high stiffness of the soil beneath the foundation inhibits the rotations more than the lateral soil and for this reason the two structures have almost the same natural period.

The results of the analysis also show that the period elongation seems to slightly reduce as the fixed base period increases. For this reason, the lateral disconnection technique could give more benefits, in terms of period elongation, especially for structures with low fixed base period. All the results could be summarizing in Figure 7 where the relative soil-structure stiffness parameter, $H /\left(V_{s} \cdot T_{\text {Fixed Base }}\right)$, is plotted against the elongation of period for different $D / B$ values. Once again, as the stiffness of the structure increases related to the stiffness of the soil the predominant period of the lateral disconnected structure will increase up to $45-50 \%$ related to the no disconnected one. 


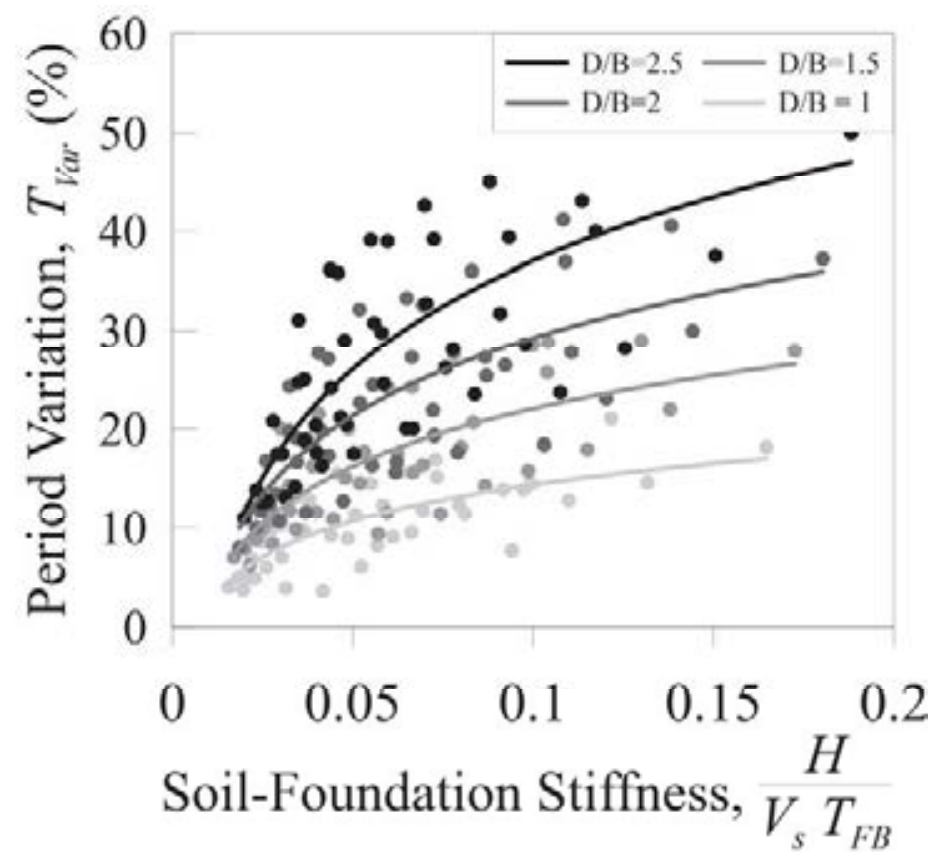

Figure 7. Period variation generated by the lateral disconnection as function of the soil-structure stiffness parameter.

\subsection{Earthquakes analysis}

Two identical structures were modelled with and without the lateral disconnection with the properties reported in Table 2 and the soil properties of section 2.2. The numerical model was then subject to the earthquakes described in Section 2.1. Figure 8 shows the roof total acceleration for Campano Lucano and Friuli earthquakes.
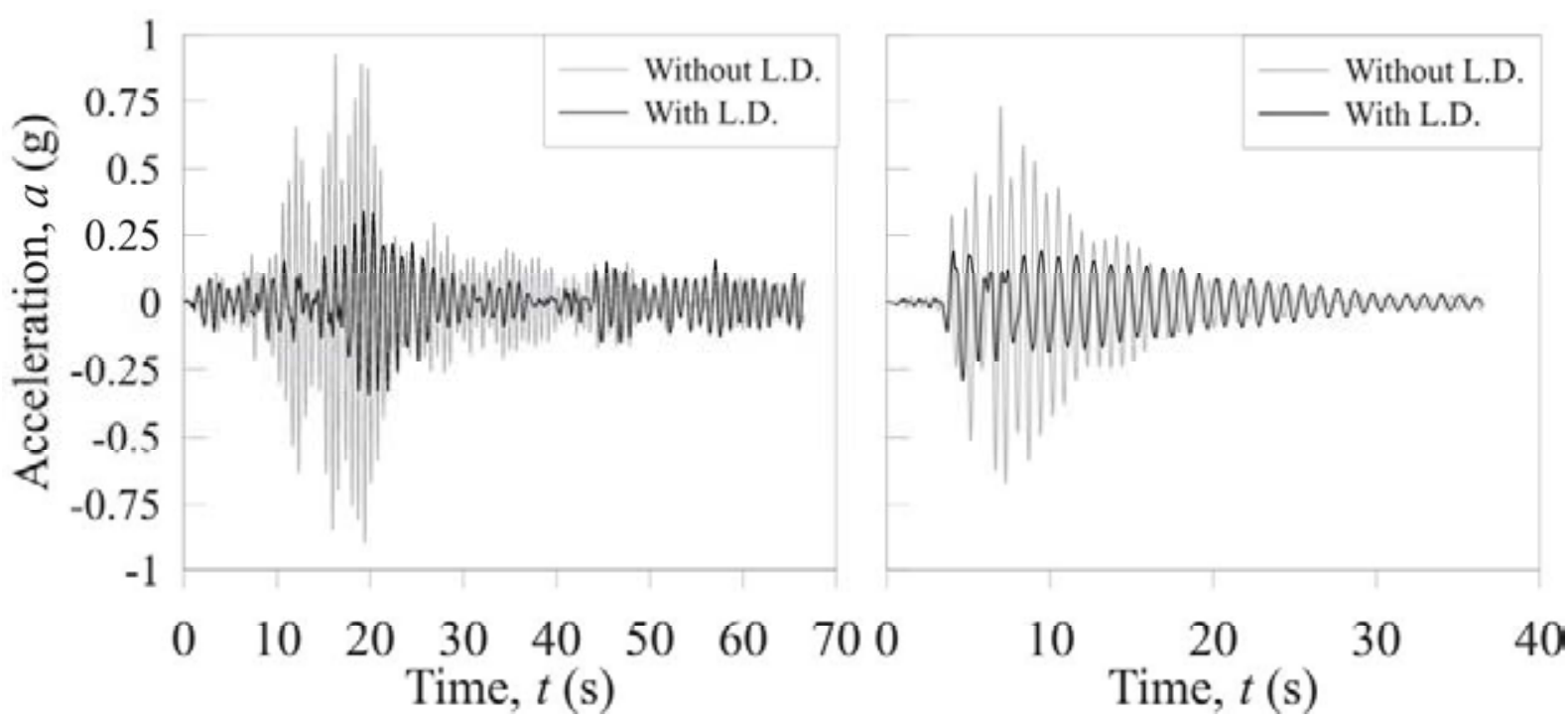

Figure 8 Total crossbeam acceleration on the two-structure considered with and without lateral disconnection: (a) Campano Lucano Earthquake; (b) Friuli Earthquake 
Due to the elongation of the predominant period generated by the lateral disconnection, the total roof accelerations are significantly different. Figure 9a shows the acceleration spectrum at the base of the structures with the indication of the elongated predominant periods.

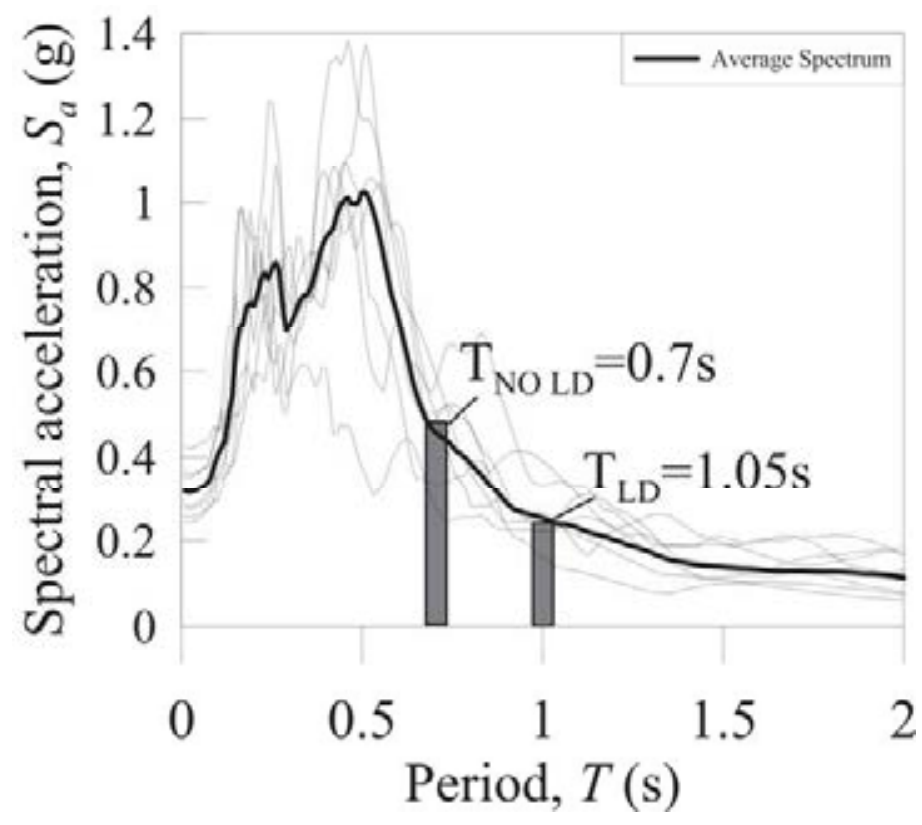

Figure 9. Response spectrum acceleration with the indication of predominant period of the structures computing the S.S.I interaction.

The Arias Intensity variation (I.A. Var $=1-I . A ., L D / I . A ., n o L D)$ and maximum total acceleration variation $\left(a_{\max } \operatorname{Var}=1-a_{\max , L D} / a_{\max , n o} L D\right)$ provided by the lateral disconnection technique is shown in Table 6 for all earthquakes.

\begin{tabular}{ccc}
\hline $\begin{array}{c}\text { Record } \\
(-)\end{array}$ & $\begin{array}{c}\text { I.A.Var } \\
(\%)\end{array}$ & $\begin{array}{c}a_{\max \text { Var }} \\
(\%)\end{array}$ \\
\hline Campano Lucano & 80 & 62 \\
Bingol & 50 & 78 \\
South Iceland & 27 & 27 \\
Mt. Vatnafjoll & 64 & 29 \\
Golbasi & 11 & 0.3 \\
Friuli & 69 & 60 \\
South Iceland(aftershock) & 2 & 5 \\
\hline
\end{tabular}

Table 6. Mitigation of the Arias Intensity and maximum total acceleration provided by the lateral disconnection. 
Moreover, the beneficial effects of the lateral disconnection technique could be seen by comparing the structural drift (Figure 10). In fact, subtracting from the total horizontal displacement of the crossbeam the horizontal displacement of the foundations and the horizontal displacement generated by the rocking rigid movement of the structure, it is possible to calculate the structural drift.
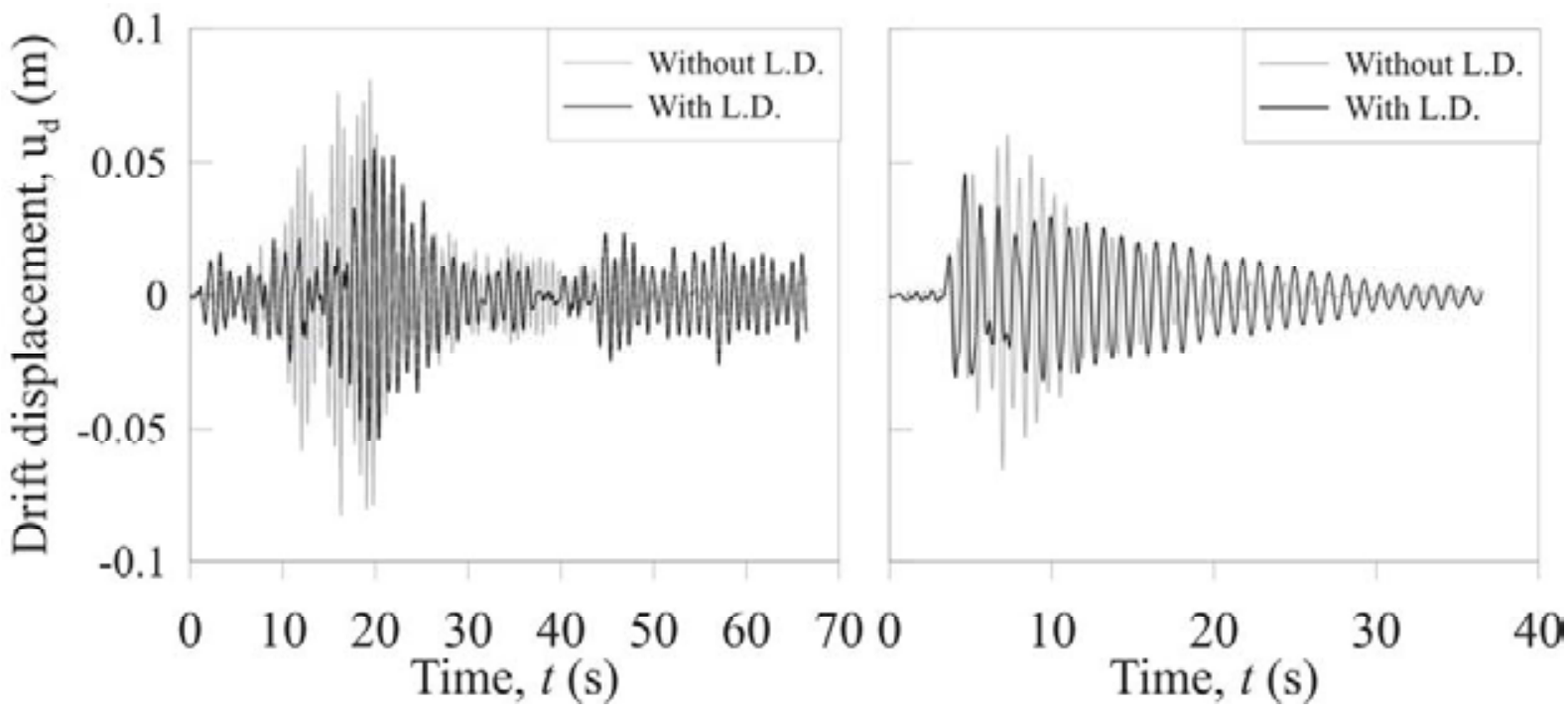

Figure 10. Drift displacement with and without the lateral disconnection: (a) Campano Lucano earthquake; (b) Friuli earthquake.

\section{CONCLUSION}

This paper has shown the potentiality of a new geo-technical seismic isolation technique called "Lateral Disconnection". The reduction of the rotational and translational foundationsoil stiffness produced by the lateral disconnection leads to a period increase related to the classical embedment condition. This period lengthening was quantified through parametric analyses where the fixed-base period, the aspect ratio of the structure and foundations and the stiffness of the ground were varied. It was found that the aspect ratio of the foundations, as well as the stiffness of the ground, plays a key role on period lengthening. The more deformable the ground is and the more founded the foundation are, the greater will the period elongation produced by the lateral disconnection be. Under certain conditions the Lateral Disconnection technique can lead to an increase up to $45-50 \%$ of the predominant period of vibration related to the classical embedment foundations.

Following the parametric analyses, a series of compatible spectral earthquakes were used to show the effectiveness of such technique in terms of seismic actions (acceleration and drift) reduction. The maximum total acceleration reduction as well as the Arias Intensity reduction could be very high, up to $60 \%$. Similar action reductions can be found if the maximum structural drift expected on the two structures is compared.

It is important to highlight that the lateral disconnection technique is not able to provide a total seismic isolation like rubber or sliding isolators but it can represent a valid seismic improvement strategy especially for its low cost and its low impact on the building. Like any antiseismic strategy, its effectiveness must be studied in detail, on the basis of the local seismic 
hazard and characteristics of the foundation, to predict, with a sufficient margin of reliability, the actions that will affect the modified structure.

\section{REFERENCES}

[1] H.H. Tsang, Geotechnical seismic isolation. Earthquake engineering: new research. Nova Science Publishers. 55-87, 2009.

[2] M.K. Yegian, M. Catan, Soil isolation for seismic protection using a smooth synthetic liner. J Geotech Geoenviron Eng. 130:1131-1139, 2004.

[3] A. Flora, D. Lombardi, V. Nappa, E. Bilotta, E., Numerical analyses of the effectiveness of soft barriers into the soil for the mitigation of seismic risk. J. Earthq. Eng. 22(1):6393, 2018.

[4] K. Pitilakis, S. Karapetrou, K. Tsagdi, Numerical investigation of the seismic response of RC buildings on soil replaced with rubber-sand mixtures. Soil Dynam Earthq Eng. 79:237-52, 2015.

[5] R. L. Kuhlemeyer, J. Lysmer, Finite Element Method Accuracy for Wave Propagation Problems. Journal of Soil Mechanics \& Foundations, Div. ASCE 99(SM5), 421-427, 1973.

[6] F.Somma, E.Bilotta, A.Flora, G.M. Viggiani. Centrifuge modelling of shallow foundations lateral disconnection to reduce seismic vulnerability. Manuscript submitted for publication, 2021.

[7] X. Jiang, Z. Yan, Earthquake response analysis of building-foundation-building interaction system. Journal of vibration engineering. 11(1), 1998.

[8] I. Iervolino, C. Galasso, E. Cosenza, REXEL: computer aided record selection for codebased seismic structural analysis. Bulletin of Earthquake Engineering, 8:339-362, 2009. DOI 10.1007/s10518-009-9146-1

[9] D.M. 17.01.2018. Nuove Norme Tecniche per le Costruzioni.

[10] BS EN 1998-1, Design of Structures for Earthquake Resistance. Eurocode 8. 3:57, 2004.

[11] E. Flavigny, J. Desrues, B. Palayer, Le sable d'Hostun. Revue Française de Géotechnique. 53:67-70, 1990.

[12] B. Hardin, V. Drnevich, Shear modulus and damping in soils: measurement and parameter effects. J. Soil Mech. Found. Div. ASCE. 98(6):603-624, 1972.

[13] E. Hoque, F. Tatsuoka, Kinematic elasticity of granular material". ISRM International Symposium, Melbourne, Australia, 2000.

[14] H.B. Seed, I. M. Idriss, Soil moduli and damping factors for dynamic response analysis. Report No EERC 70-10, University of California, Berkeley, California, USA, 1970. 